\title{
Organophosphorus pesticide residues in soils and drinking water sources from cocoa producing areas in Ghana
}

\author{
Benedicta Yayra Fosu-Mensah ${ }^{1 *}$, Elvis Dartey Okoffo ${ }^{1}$, Godfred Darko² and Christopher Gordon
}

\begin{abstract}
Background: Pests and diseases are recognised as major factors responsible for the decline in cocoa yield in Ghana. This has resulted in an increased use of pesticides to increase productivity. The regular application and indiscriminate use of chemicals have been associated with unintended environmental and human health consequence. The objective of this study was to determine levels of 13 organophosphorus pesticide residues in soils and drinking water sources in and around cocoa farms in Brong Ahafo region of Ghana.
\end{abstract}

Methods: Organophosphorus pesticide residues were determined by the use of a high resolution Varian CP-3800 Gas Chromatograph equipped with pulse flame photometric detector (PFPD) in 32 soils and 64 drinking water samples from 16 cocoa farms in the Dormaa West District of Ghana.

Results: Four organophosphorus residues were detected in the soil and water samples at varying concentrations. The organophosphorus residues detected in soil samples were chlorpyrifos $(0.01-0.04 \mathrm{mg} / \mathrm{kg})$, profenofos $(0.02-0.04 \mathrm{mg} / \mathrm{kg})$ and pirimiphos-methyl $(0.01-0.04 \mathrm{mg} / \mathrm{kg})$ while the organophosphorus residues recorded in the water samples were chlorpyrifos $(0.01-0.05 \mu \mathrm{g} / \mathrm{L})$, diazinon $(0.01-0.04 \mu \mathrm{g} / \mathrm{L})$ and pirimiphos-methyl $(0.01-0.03 \mu \mathrm{g} / \mathrm{L})$. The concentrations of organophosphorus pesticide residues in the soil samples analysed from the various sites were generally below and within US MRLs for agricultural soils. However, mean concentrations of chlorpyrifos and pirimiphos-methyl recorded at Nkrankwanta (S1) were found to be above their respective US MRLs for agricultural soils. The trends of organophosphorus pesticide residues in the water samples analysed from the various distances to cocoa farms decreased with increase in distance to cocoa farm (ranking; 0-15>16-30> above $30 \mathrm{~m}$ ). All organophosphorus pesticide residues recorded in the water samples from the various sites within the various distances were below and within their respective WHO MRLs for drinking water except chlorpyrifos at Diabaa (S2) and Kwakuanya (S4) at distance 16-30 $\mathrm{m}$ and diazinon at Kwakuanya (S4) at a distance 0-15 m which exceeded their WHO MRLs. There were no significant $(p>0.05)$ sites differences in mean values of pesticide residues detected in soils and water samples.

Conclusions: The presence of organophosphorus in the samples analysed was an indication of the use of the pesticides by cocoa farmers in the study area to control pest and diseases. The pesticide residues in the soil poses danger to soil organisms as well as contaminate surrounding water bodies through runoff and leaching. In addition, there is the likelihood of translocation of these residues from the soil into the cocoa beans and other crops (like vegetables that are commonly intercropped with cocoa) through the root system, thereby posing health risks to consumers. Chlorpyrifos and diazinon concentrations in drinking water exceeded their respective WHO MRLs at some sampled sites and may pose health hazard to farmers' household and the communities.

Keywords: Organophosphorus, Pollution, Pesticides residues, Environment, Monitoring

\footnotetext{
*Correspondence: yayramensah@staff.ug.edu.gh

1 Institute for Environment and Sanitation Studies (IESS), University

of Ghana, P. O. Box 209, Legon, Accra, Ghana

Full list of author information is available at the end of the article
}

\section{贷 Springer}

(C) 2016 Fosu-Mensah et al. This article is distributed under the terms of the Creative Commons Attribution 4.0 International License (http://creativecommons.org/licenses/by/4.0/), which permits unrestricted use, distribution, and reproduction in any medium, provided you give appropriate credit to the original author(s) and the source, provide a link to the Creative Commons license, and indicate if changes were made. 


\section{Background}

The increase in the use of pesticides in Ghana is as a result of the need to increase crop productivity to feed the ever increasing population. This is particularly true in the subhumid ecological zones where prevailing environmental conditions are conducive to increase the provenience of insect pests and diseases. The nuisance of pests and diseases is recognised as a strong factor responsible for the dwindling yield of cocoa in Ghana (Abekoe et al. 2002) with its adverse consequences for the country's economy. As a result the application of synthetic pesticides have been a measure to control pests and diseases in order to increase yields (Dankyi et al. 2014). However, regular and repeated application of pesticides on cocoa trees throughout cocoa seasons, coupled with the indiscriminate use and inappropriate handling of the chemicals by farmers has often been associated with unintended environmental and human health consequences (Fianko et al. 2011; Dankyi et al. 2014).

Contamination of the natural environment with pesticides especially organochlorine have been a major concern to researchers because of their toxicity and threat to human, soil, water, animal and plant health (Afful et al. 2010; Fianko et al. 2011). Pesticides reaching the soil after spraying may affect soil quality by disturbing some soil organisms such as earthworms, microbes and natural enemies which acts as decomposers (Ntiamoah and Afrane 2008). This may decreases soil microbial biomass by directly killing or influencing activities such as behaviour, reproduction and metabolism of organism which may permanently impair and alter the closely interactive ecosystem (Aktar et al. 2009; Gill and Garg 2014).

Pesticide residues in soils have the potential to cause toxicity to plants, their products and contaminate the food chain when taken up by plants roots. In addition, pesticide residues in soil and the environment have the tendency to pollute groundwater and surface water through leaching and surface runoffs, thereby increasing the risk of environmental contamination. Increased accumulation of pesticide residues in the food chain and drinking water have been reported to pose serious human health hazards (Akan et al. 2013; Agbeve et al. 2014). For instance, exposure to pesticide residues through food and drinking water are reported to affect thyroid function, cause low sperm count in males, birth defects, increase in testicular cancer, reproductive (Mesnage et al. 2010) and immune malfunction (Tanner et al. 2011), endocrine disruptions, cancers, immunotoxicity (Cocco et al. 2013), neuro behavioural and developmental disorders (Gill and Garg 2014).

However, in the past few years, studies on pesticide residues in the Ghanaian cocoa industry have shown that significant amount of applied pesticides ends up in cocoa growing soils (Bentum et al., 2006) and cocoa beans
(Botchway 2000; Apau and Dodoo 2010; Owusu-Ansah et al. 2010; Frimpong et al. 2012a, b, c, d). Unfortunately, these few available reports on the levels of pesticides contamination in the cocoa industry have concentrated much more on organochlorines which are banned or restricted for use in cocoa production, with little information on the residual levels of organophosphorus which are approved for agricultural and household purposes in Ghana (Environmental Protection Agency (EPA) 2009).

In view of the public health significance of pesticide residues and the uncertainty that exist regarding the long term effects of low dose exposure of these pesticides to human and the environment, it is important to assess their levels in the environment.

Dormaa West District is one of the major cocoa producing districts in the Brong Ahafo region of Ghana (Ghana Statistical Service 2014). Over the years, pests and diseases has been a major challenge affecting cocoa production in the district. This has resulted in an increased use of pesticides to control pest and diseases in order to increase cocoa productivity. The increased use of these chemicals may negatively impact on the quality of soils and drinking water sources in and around cocoa farms. There is however little information on levels of pesticide residues in soils and water sources from cocoa farms in the district. This study therefore aims at assessing the levels of organophosphorus pesticide residues in soils and drinking water sources from some selected cocoa producing communities in the Dormaa West District of Ghana. This information will assist in a scientific assessment of the impacts of pesticides on public health, agriculture and the environment.

\section{Methods}

\section{Study area}

The study was carried out in the Dormaa West District located in the western part of the Brong Ahafo Region of Ghana (Fig. 1). The district is generally an agrarian economy which contributes immensely to the food basket of the country. Agriculture is the main source of employment (82\%) in the district (Ghana Statistical Service 2014). The major economic activities in the district include the cultivation of food and cash crops (including cocoa), poultry and livestock farming, oil palm extraction, cassava processing and sand winning. The area is well drained by a network of rivers (Bia, Nkasapim and Pamu).

\section{Sampling design}

Four cocoa growing communities namely Nkrankwanta (S1), Diabaa (S2), Krakrom (S3) and Kwakuanya (S4) were randomly selected from the district. Sixteen (16) cocoa farms (four farms from each community) were 


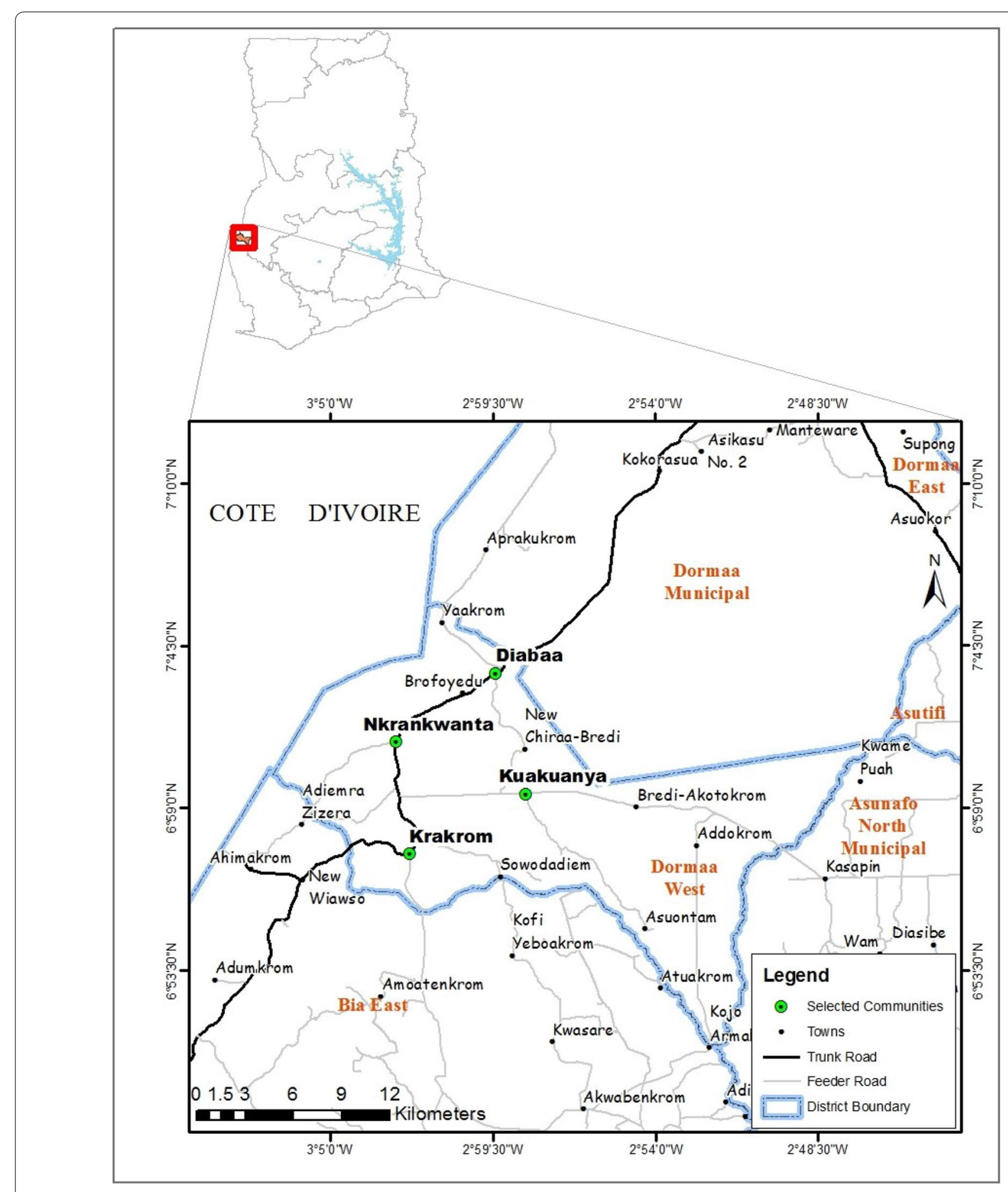

Fig. 1 Map of Dormaa West District showing selected communities

identified purposively with (i) Distance of farm to the nearest drinking water source (hand dug wells) and (ii) age of cocoa farm (farms not less than 8 years and not more than 20 years with a history of at least 5 years of pesticides application) being the determining factors. Soils and water samples were sampled from December
2014 to February 2015. Sampling was not timed to applications of different pesticides or to rain events.

\section{Soil sampling}

In each of the selected cocoa farms, two quadrats of $80 \times 80 \mathrm{~m}$ were marked. In each quadrat, five (5) core 
soil samples were collected randomly at depth $0-20 \mathrm{~cm}$ with a soil auger and put together to form a composite sample. The composite soil samples were well mixed and sub-samples taken. Two soil replicates were collected from each cocoa farm. These gave a total of 32 soil samples from the study area. All soil samples were kept in well-labelled sampling bags and transported to the laboratory for analysis. At the laboratory, the soil samples were oven-dried at $105^{\circ} \mathrm{C}$ to constant weight and sieved using $2 \mathrm{~mm}$ nylon mesh. Sub-samples of the sieved soils were then taken for pesticide residues analysis.

\section{Water sampling and physico-chemical analysis}

Water samples were collected from 19 hand dug wells (drinking water sources) located within and/or around cocoa farms selected for the study. Wells were selected based on distance to cocoa farms in the order; 0-15 m and $16-30 \mathrm{~m}$, whiles wells above $30 \mathrm{~m}$ were used as control. These distances were chosen because the World Health Organization (WHO) recommends that hand dug wells should be at least $30 \mathrm{~m}$ away from an agricultural field where chemicals are handled (Harris et al. 1996; WHO 2004). Water samples were collected from two hand dug wells from each of the distance categories (between 0-15 and 16-30 m) within each selected community. Water samples were also collected from three open wells at above $30 \mathrm{~m}$ distance to serve as control. Three replicates were collected from each well making a total of sixty-four (64) water samples.

A water sampler was used to collect water samples into $1.5 \mathrm{~L}$ and $500 \mathrm{~mL}$ pre-cleaned polyethylene sample bottles with caps for pesticide residues and physico-chemical analysis respectively. All the wells were shallow wells $(<15 \mathrm{~m})$ which represent unconfined aquifers. The sampling bottles were rinsed with well water before taking the water samples. The samples were labelled and transported to the laboratory [Ecological Laboratory (ECOLAB), of University of Ghana, Legon] within 24-48 h on ice in clean ice chests and stored in the refrigerator at $4{ }^{\circ} \mathrm{C}$ until they were analysed for physico-chemical parameters and pesticide residues. The samples for pesticide residues analysis were extracted within $24 \mathrm{~h}$ of arrival at the laboratory.

The physicochemical parameters analysed included: $\mathrm{pH}$, electrical conductivity, temperature, total dissolved solids, turbidity, nitrate, ammonia, phosphate, total suspended solids, sodium and potassium. All the analytical procedures used in the physicochemical analysis of the water samples were done according to standard method of water analysis (APHA 1998). Physico-chemical parameters such as $\mathrm{pH}$, electrical conductivity, temperature and total dissolved solids were measured in situ using a Multi-parameter meter (Model YSI 63) manufactured by YSI incorporated, USA. They were measured concurrently. The measuring equipment (Multi-parameter meter Model YSI 63) was first calibrated with standard $\mathrm{pH}$ buffers before immersing the probe into the water. Turbidity was measured using a turbidity meter (Model $\mathrm{HACH} 2100 \mathrm{P}$ ) manufactured by HACH USA. Calibration of the turbidity meter was done by filtering some water samples through pre-weighed Whatman GF/F $(0.45 \mu \mathrm{m}$ pore-size) glass microfiber filters. Nitrate, ammonia, phosphate and total suspended solids were analysed using $\mathrm{HACH}$ direct reading spectrophotometer (Model DR. 2010) manufactured by HACH, USA. Sodium and potassium ions were analysed employing the flame emission photometric method using Gallenkamp digital flame analyser (Loughborough, England).

\section{Determination of pesticide residues in soils and water samples \\ Chemicals and reagents used}

Soil and water samples were analysed for 13 organophosphorus pesticides. The thirteen organophosphorus pesticide reference standards (methamidophos, ethoprophos, phorate, diazinon, fonofos, dimethoate, pirimiphosmethyl, chlorpyrifos, malathion, fenitrothion, parathion, chlorfenvinphos and profenofos) were purchased from Dr. Ehrenstorfer GmbH (Augsburg, Germany). Pesticides grade acetonitrile and dichloromethane were purchased from BDH, England. Silica gel adsorbents were obtained from Phenomenex, USA. In addition, all other reagents and solvents used were of analytical grade purchased from BDH, England and included: anhydrous magnesium sulphate, anhydrous sodium sulphate, acetone, ethyl acetate, and saturated sodium chloride.

\section{Standard solutions}

Stock solutions $(100 \mathrm{mg} / \mathrm{mL})$ of the thirteen organophosphorus pesticide standards were prepared by pipetting the appropriate aliquot or weight of the organophosphorus pesticides into $25 \mathrm{~mL}$ volumetric flasks, and then dissolving and diluting to the marks with ethyl acetate with the aid of a vortex mixer (Thermolyne Maxi Mix-Plus). Working solutions of standards for fortification standards in the procedural recovery process, and as calibration standards in the instrument calibration were freshly prepared through dilution of an appropriate aliquot of the stock solutions with ethyl acetate. Distilled water was used to prepare all aqueous solutions. All solutions prepared for Gas Chromatography (GC) were filtered through a $0.45 \mu \mathrm{m}$ nylon filter.

\section{Extraction of soil samples}

The extraction of the soil samples was carried out by the method described by Frimpong et al. (2013), with slight 
modification from the Ghana Standard Authority's (GSA) Pesticides Residue laboratory Protocols. Ten gram (10 g) of the representative soil samples were weighed and quantitatively transferred into $250 \mathrm{~mL}$ separating flasks. A $10 \mathrm{~mL}$ of acetonitrile was added to each of the soil samples in the flasks and ultra-sonicated (Becon FS400b) for $5 \mathrm{~min}$. An additional $10 \mathrm{~mL}$ of acetonitrile was added, and the flasks closed tightly. The samples were placed on a horizontal mechanical shaker (Ika-Werke HS 501 Digital) and set to shake continuous for $30 \mathrm{~min}$ at $300 \mathrm{mot} /$ $\mathrm{min}$. The contents were then allowed to stand for $10 \mathrm{~min}$ to sufficiently separate the phases or layers. A $10 \mathrm{~mL}$ of the supernatants were carefully taken by pipette and dried over $2 \mathrm{~g}$ anhydrous magnesium sulphate through filter paper into $50 \mathrm{~mL}$ round bottom flasks. The concentrates were then adjusted to about $2 \mathrm{~mL}$ using the rotary film evaporator (Buchi Ratovapor R-210, USA) at $35^{\circ} \mathrm{C}$, and made ready for silica clean up step.

\section{Clean-up of soil extract}

The silica gel clean-up process for the soil extracts were carried out by the methods described by Frimpong et al. (2013), with slight modifications from the Ghana Standard Authority (GSA) Pesticides Residue Laboratory protocols. Extracts clean up were done, using polypropylene cartridge columns, packed with one-gram silica gel previously activated for $10 \mathrm{~h}$ in an oven at $130^{\circ} \mathrm{C}$, which have $1 \mathrm{~cm}$ thickness layer of anhydrous magnesium sulphate on top and conditioned with $6 \mathrm{~mL}$ acetonitrile. The concentrated extracts were then loaded onto the columns/ cartridges, and $50 \mathrm{~mL}$ pear shape flasks placed under the columns to collect the eluates. A $10 \mathrm{~mL}$ acetonitrile was used to elute the columns/cartridges afterwards. The total filtrates (eluents) collected were concentrated to dryness using the rotary evaporator (Buchi Ratovapor $\mathrm{R}$-210) set at $40{ }^{\circ} \mathrm{C}$. The residues were re-dissolved in $1 \mathrm{~mL}$ ethyl acetate by pipetting and transferred into $2 \mathrm{~mL}$ standard opening vials prior to quantitation by gas chromatography (GC) (Varian Association Inc. USA) equipped with pulse flame photometric detector (PFPD). All extracts were kept frozen until quantification was achieved.

\section{Extraction of water samples}

The extraction technique employed for water samples in this work was as described by Afful et al. (2013), with slight modification from the Ghana Standard Authority's (GSA) Pesticides Residue Laboratory protocols. After filtration of water samples through $0.45 \mathrm{~mL}$ fiber glass filters (WHATMAN) to remove debris and suspended material, $1000 \mathrm{~mL}$ portions of the filtered water samples were transferred into $2 \mathrm{~L}$ capacity separating flasks. A $30 \mathrm{~mL}$ of saturated sodium chloride solution $(\mathrm{NaCl})$ was added to each to produce a salt out effect in order to adjust the $\mathrm{pH}$ from 3.5 to 4 . The samples were then thoroughly mixed by inverting the flask three to four times. A $100 \mathrm{~mL}$ of dichloromethane as extraction solvent was then added to each sample and vigorously shaken manually for 2-3 min, while releasing the pressure intermittently. The phases were allowed to separate for $5 \mathrm{~min}$ and the dichloromethane extracts (organic layers) were separated from the aqueous layers. The extraction for each water sample was repeated twice with $100 \mathrm{~mL}$ of dichloromethane and the organic layers put together and dried over anhydrous sodium sulphate through filter papers into $50 \mathrm{~mL}$ round bottom flasks. The extracts from the water samples were then concentrated on rotary vacuum evaporators (Buchi Ratovapor R-210, USA) to about $1 \mathrm{~mL}$ and subjected to silica clean up.

\section{Clean-up of water Extract}

The silica gel clean-up process for the water extracts were carried out by the methods described by Afful et al. (2013), with slight modifications from the Ghana Standard Authority's (GSA) Pesticides Residue Laboratory protocols. Extracts clean up were done, using polypropylene cartridge columns, packed with one-gram silica gel previously activated for $10 \mathrm{~h}$ in an oven at $130{ }^{\circ} \mathrm{C}$, which have $2 \mathrm{~g}$ layer of anhydrous sodium sulphate on top and conditioned with $6 \mathrm{~mL}$ dichloromethane. The concentrated extracts were then loaded onto the cartridges, and $100 \mathrm{~mL}$ round bottom flasks were placed under the columns to collect the eluates. A $20 \mathrm{~mL}$ dichloromethane was then used to elute the columns/cartridges afterwards, and the total filtrates (eluents) collected were concentrated just to dryness using the rotary evaporator (Buchi Ratovapor R-210) set at $40{ }^{\circ} \mathrm{C}$. The residues were re-dissolved in $1 \mathrm{~mL}$ ethyl acetate by pipetting and transferred into $2 \mathrm{~mL}$ standard opening vials prior to quantitation by gas chromatography (GC) (Varian Association Inc. USA) equipped with pulse flame photometric detector (PFPD). All extracts were kept frozen until quantification was achieved.

\section{Gas chromatographic determination}

The final extracts were analysed by a gas chromatography (GC)-Varian CP-3800 (Varian Association Inc. USA) equipped with pulse flame photometric detector (PFPD) and CombiPAL Autosampler at the Ghana Standards Authority's (GSA) Pesticide Residues Laboratory, Accra, Ghana. The GC conditions and the detector response were adjusted so as to match the relative retention times and response as spelt out by the Japanese analytical methods for agricultural chemicals (Syoku-An 2006). The GC conditions used for the analysis were capillary column (fused silica capillary) coated with VF-1701 ms 
$(30 \mathrm{~m} \times 0.25 \mathrm{~mm}$ internal diameter, $0.25 \mu \mathrm{m}$ film thickness). The injector and detector-PFPD temperatures were set at 270 and $280^{\circ} \mathrm{C}$ respectively. The oven temperature was programmed as follows: $70^{\circ} \mathrm{C}$ held for $2 \mathrm{~min}$, ramp at $25^{\circ} \mathrm{C} \mathrm{min}{ }^{-1}$ to $200{ }^{\circ} \mathrm{C}$, held for $1 \mathrm{~min}$, and finally ramp at $25^{\circ} \mathrm{C} \mathrm{min}{ }^{-1}$ to $250^{\circ} \mathrm{C}$. Nitrogen was used as carrier gas at a constant flow rate of $2.0 \mathrm{~mL} / \mathrm{min}$ and detector makeup gases of $17.0,14.0$ and $10.0 \mathrm{~mL} / \mathrm{min}$ for air 1 , hydrogen and air two respectively. The injection volume of the GC was $2.0 \mu \mathrm{L}$ in a split less mode. The total run time for a sample was $14 \mathrm{~min}$.

\section{Quality assurance and quality control}

Proper quality assurance procedures and precautions were taken to ensure the reliability of the results. The samples were carefully handled to avoid any external influences that could interfere with the integrity of the sample and hence contaminate it. All glassware's were rigorously washed with detergent, rinsed with distilled water, thoroughly rinsed with analytical grade acetone and dried overnight in an oven at $150{ }^{\circ} \mathrm{C}$. The glassware's were then removed from the oven and allowed to cool down and stored in dust-free cabinets. Deionized water was used throughout the study. For the spectrophotometric analysis, reagent blank determinations were used to correct the instrument readings. For validation of the analytical procedure, repeated analysis of the samples against internationally certified/standard reference material (SRM-1570) of National Institute of Standard and Technology were used. The quality of organophosphorus pesticide residues was assured through the analysis of solvent blanks, procedural matrix blanks and duplicate samples. All reagents used during the analysis were exposed to same extraction procedures and subsequently run to check for interfering substances. In the blank for each extraction procedure, no pesticide was detected. A sample of each series was analysed in duplicates. All extracts were kept frozen until quantification was done. Recalibration curves were run with each batch of samples to check that the correlation coefficient was kept around $\mathrm{r}^{2}=0.99$. A fortification level of $0.01 \mathrm{mg} / \mathrm{kg}$ for soil and $0.01 \mu \mathrm{g} / \mathrm{L}$ for water were chosen before the analysis to evaluate the recovery of the compounds in both soil and water samples. The efficiency of the analytical methods (the extraction and clean-up methods) was determined by recoveries of an internal standard. The recoveries of internal standards ranged between 70 and $94 \%$ for all the organophosphorus pesticide analysed. These recovery values shows that the method used is reproducible.

\section{Quantification and limit of detection of pesticides}

The residue levels of organophosphorus pesticides were quantitatively determined by the external standard method using peak area. Measurement was carried out within the linear range of the detector following the procedures of Frimpong et al. (2012a), (2012c), Afful et al. (2013) and Frimpong et al. (2013). The peak areas whose retention times coincided with the standards were extrapolated on their corresponding calibration curves to obtain the concentration. The limit of detection of the pesticides determined was based on the extract of the fortified samples that were serially diluted by factor of two to give different concentrations. One out of each concentration that gave a response three times the standard deviation of the least fortified sample was noted. This was used to estimate the statistical significance of differences between low level analyte responses and the combined uncertainties in both the analyte and the background measurement. The limits of detection for the organophosphorus pesticides in soil and water samples were $0.01 \mathrm{mg} / \mathrm{kg}$ and $0.01 \mu \mathrm{g} / \mathrm{L}$ respectively.

\section{Data analysis}

Statistical package for social sciences (SPSS) software version 20.0 was used to generate the means for the physico-chemical parameters of water as well as the pesticide residues in soil and water. One-way analysis of variance (ANOVA) was performed to analyse significant differences in the physico-chemical properties measured and the concentrations of pesticide residues recorded from the different sites and distances. Pearson's correlation analysis was performed to determine the relationship between the levels of pesticide residues and the physico-chemical characteristics of water. The statistical significance tests were carried out at $5 \%$ confidence level $(p<0.05)$.

\section{Results and discussion}

\section{Physico-chemical properties of water samples}

Table 1 summarizes the physico-chemical properties of water samples collected from the various distance categories in relation to cocoa farms in the study area.

The temperatures recorded ranged from 25.9 to $27.9^{\circ} \mathrm{C}$ with a mean value of $27.0 \pm 0.72{ }^{\circ} \mathrm{C}$. However, there were no significant differences $(p>0.05)$ in temperature with respect to distances of water source to cocoa farms. With the exception of water samples from $\mathrm{S} 1\left(32.3^{\circ} \mathrm{C}\right)$ at a distance 16-30 m, samples from all the other sites within the various distance categories recorded mean temperature values that were within the WHO permissible limit of $22-29^{\circ} \mathrm{C}$ for drinking water (WHO 1998).

The mean $\mathrm{pH}$ recorded for the entire study was $5.51 \pm 0.23$. There were no significant differences $(p>0.05)$ in $\mathrm{pH}$ with respect to distances of water source to cocoa farms. However, with the exception of water samples from S4 (6.93) at a distance $0-15 \mathrm{~m}$ which 
Table 1 Summary of physico-chemical characteristics of water samples from the study area

\begin{tabular}{|c|c|c|c|c|c|c|c|c|}
\hline \multirow{2}{*}{$\begin{array}{l}\text { Distance (m) } \\
\text { Parameters }\end{array}$} & \multicolumn{2}{|l|}{$0-15 \mathrm{~m}$} & \multicolumn{2}{|l|}{$16-30 \mathrm{~m}$} & \multicolumn{2}{|c|}{ Above $30 \mathrm{~m}$} & \multirow{2}{*}{$\begin{array}{l}\text { Total means } \\
\text { Mean } \pm \text { SD }\end{array}$} & \multirow{2}{*}{$\begin{array}{l}\text { WHO } \\
\text { recommended } \\
\text { limits }\end{array}$} \\
\hline & Range & Mean \pm SD & Range & Mean \pm SD & Range & Mean \pm SD & & \\
\hline Temperature $\left({ }^{\circ} \mathrm{C}\right)$ & $25.3-26.4$ & $25.9 \pm 0.41$ & $25.9-32.3$ & $27.9 \pm 2.31$ & $26.0-28.0$ & $27.2 \pm 1.16$ & $27.0 \pm 0.72$ & $22-29$ \\
\hline $\mathrm{pH}$ & $5.05-6.93$ & $5.82 \pm 0.62$ & $5.34-5.86$ & $5.54 \pm 0.17$ & $4.80-5.42$ & $5.18 \pm 0.33$ & $5.51 \pm 0.23$ & $6.5-8.5$ \\
\hline Conductivity ( $\mu \mathrm{S} / \mathrm{cm})$ & $73.0-233.0$ & $134.0 \pm 54.4$ & 74.0-198.0 & $129.0 \pm 41.5$ & $60.0-148.0$ & $93.0 \pm 47.5$ & $118.7 \pm 15.8$ & 1000 \\
\hline TDS (mg/L) & $36.0-110.0$ & $65.5 \pm 25.0$ & $37.0-98.0$ & $64.3 \pm 20.5$ & $30.0-73.0$ & $46.3 \pm 23.3$ & $58.7 \pm 7.61$ & 1000 \\
\hline Turbidity (NTU) & $3.87-205.0$ & $63.6 \pm 23.3$ & $1.77-121.0$ & $41.2 \pm 6.21$ & $1.25-2.87$ & $2.29 \pm 0.91$ & $35.8 \pm 21.9$ & 5 \\
\hline TSS (mg/L) & $6.00-277.0$ & $70.0 \pm 26.8$ & $3.00-126.0$ & $40.0 \pm 5.45$ & $2.00-6.00$ & $4.00 \pm 2.08$ & $38.0 \pm 23.4$ & \\
\hline Nitrate (mg/L) & $1.00-12.80$ & $5.90 \pm 3.80$ & $2.90-6.50$ & $4.00 \pm 1.30$ & $0.40-4.00$ & $2.20 \pm 0.87$ & $4.03 \pm 1.31$ & 10 \\
\hline Ammonia (mg/L) & $0.17-3.88$ & $1.25 \pm 0.56$ & $0.32-1.38$ & $0.66 \pm 0.37$ & $0.15-0.22$ & $0.18 \pm 0.04$ & $0.69 \pm 0.38$ & 0.5 \\
\hline Phosphate (mg/L) & $0.49-1.22$ & $0.75 \pm 0.25$ & $0.48-1.22$ & $0.77 \pm 0.26$ & $0.32-1.04$ & $0.67 \pm 0.36$ & $0.73 \pm 0.04$ & \\
\hline Sodium (mg/L) & $7.10-17.5$ & $11.8 \pm 3.38$ & $10.4-26.2$ & $18.6 \pm 5.05$ & $12.2-26.2$ & $17.1 \pm 7.86$ & $15.8 \pm 2.53$ & 200 \\
\hline Potassium (mg/L) & $1.90-6.70$ & $4.45 \pm 1.54$ & $1.10-6.10$ & $3.30 \pm 1.61$ & $2.40-3.70$ & $2.90 \pm 0.67$ & $3.55 \pm 0.57$ & 30 \\
\hline
\end{tabular}

SD standard deviation, TDS total dissolved solids, TSS total suspended solids

recorded a mean $\mathrm{pH}$ value that was within the WHO acceptable limits of 6.5-8.5 for drinking water (WHO 2004 ), all the other sites within the various distances recorded mean $\mathrm{pH}$ values that were below the WHO acceptable limits for drinking water. The low $\mathrm{pH}$ values recorded could be due to the amount of acidic cations present in the soil due to the leaching of basic cations or the presence of high level of organic matter within the soil zones whose oxidation releases carbon dioxide that reacts with water to produce a weak carbonic acid (Langmuir 1997; Kortatsi 2007).

A mean conductivity value of $118.7 \pm 15.8 \mu \mathrm{S} / \mathrm{cm}$ was recorded for the entire study. The conductivity values recorded during the study were generally low for all the sites and fell within the permissible limit of $1000 \mu \mathrm{S} /$ $\mathrm{cm}$ for drinking water (WHO 2004). There were no significant differences $(p>0.05)$ in electrical conductivity among the sampling distances.

The mean total dissolved solids (TDS) recorded was $58.7 \pm 7.61 \mathrm{mg} / \mathrm{L}$. There were no significant differences $(p>0.05)$ in the mean values of TDS among the various distances of water source to cocoa farms. The TDS measured in the water samples were all below the guideline limit of $1000 \mathrm{mg} / \mathrm{L}$ for drinking water (WHO 2004), indicating that the groundwater were generally fresh and have no particulate content.

Turbidity in water is the reduction of transparency due to the presence of suspended particles (Fianko et al. 2013). Measured turbidity values ranged from 2.29-63.6 NTU. There were, however, no significant difference $(p>0.05)$ in turbidity in relation to distances of water source to cocoa farms. With the exception of water samples from S2 (3.87 NTU) at a distance 0-15 m, S4
(1.77 NTU) at a distance 16-30 $\mathrm{m}$ and S5 (2.29 NTU) at a distance above $30 \mathrm{~m}$ (control), all the other sites within the various distances recorded mean turbidity values that far exceeded the WHO permissible limit of 5 NTU. The high turbidity values may be due to erosion and run-off from cocoa farms which carried soil particles and deposited them in the wells as most of them were not protected. It could have also been due to the shallow nature of the well resulting in disturbance and re-suspension during water withdrawal from the wells.

Total suspended solids (TSS) are solids in water that can be trapped by a filter (Fianko et al. 2013). The mean TSS measured for the study was $38.0 \pm 23.4 \mathrm{mg} / \mathrm{L}$. Similarly, there were no significant differences $(p>0.05)$ in TSS in relation to distances of water source to cocoa farms. Although, TSS in drinking water does not have a WHO health based guideline limit, it is recommended that it should not exceed $500 \mathrm{mg} / \mathrm{L}$ in water for drinking (Ewusi et al. 2013). The mean TSS values recorded at all sampled sites within the various distances (3.00$227.0 \mathrm{mg} / \mathrm{L}$ ) were below this recommended limit. The low values recorded in this study may be as a result of the filtering capacity of the soil and earth materials.

The nitrate concentrations recorded for the study ranged from 2.20 to $5.90 \mathrm{mg} / \mathrm{L}$ with a mean of $4.03 \pm 1.31 \mathrm{mg} / \mathrm{L}$. There were however no significant differences $(p>0.05)$ in nitrate values recorded in relation to distances of water source to cocoa farms. However, with the exception of water samples from S3 $(12.8 \mathrm{mg} / \mathrm{L})$ at a distance 0-15 m, samples from all the other sites within the various distances recorded mean nitrate values that were below the WHO permissible concentration level of $10 \mathrm{mg} / \mathrm{L}$ for drinking water. The high concentration level 
of nitrates recorded at S3 may be due to leaching and run-off of nitrogen based mineral fertilizers from cocoa farms which were close to the water source.

The mean ammonia concentration recorded in this study was $0.69 \pm 0.38 \mathrm{mg} / \mathrm{L}$. There were no significant differences $(p>0.05)$ in ammonia in relation to distances of water source to cocoa farms. However, with the exceptions of water samples from S4 at a distance $0-15 \mathrm{~m}$ and $\mathrm{S} 1$ at a distance of $16-30 \mathrm{~m}$ which recorded mean ammonia values ( 3.88 and $1.38 \mathrm{mg} / \mathrm{L}$ respectively) above WHO guideline, samples from all the other sites within the various distances from cocoa farms recorded mean ammonia values that were within the $\mathrm{WHO}$ guideline value of $0.5 \mathrm{mg} / \mathrm{L}$ (Tay 2007). The high concentration of ammonia recorded at S4 and S1 may be as a result of leaching of applied fertilizers and/or run-off at those sites as these wells were in close proximity to cocoa farms.

The average phosphate concentration recorded in the study was $0.73 \pm 0.04 \mathrm{mg} / \mathrm{L}$. Similarly, there were no significant differences $(p>0.05)$ in phosphate concentrations in relation to distances of water source from cocoa farms. Although there is no WHO guideline value, phosphate may not be toxic to humans unless they are present in very high levels where digestive problems could occur. Phosphate concentrations in the water samples were generally lower compared to the values of $0.33-$ $9.30 \mathrm{mg} / \mathrm{L}$ reported by Nkansah et al. (2010) in hand-dug wells in the Kumasi metropolis of Ghana. The low phosphate levels recorded in this study may possibly be due to its adsorption by soils as well as phosphate deficiency in Ghanaian soils hence, applied phosphate might have been used up by cocoa plants as reported by Ewusi et al. (2013).

The mean sodium concentrations recorded ranged from 11.8 to $18.6 \mathrm{mg} / \mathrm{L}$ with a mean value of $15.8 \pm 2.53 \mathrm{mg} / \mathrm{L}$. The mean sodium values recorded for all the sites within the various distances from cocoa farms during the entire study period fell within the permissible limit of $200 \mathrm{mg} / \mathrm{L}$ for drinking water (WHO 1998). There were no significant differences $(p>0.05)$ in sodium in relation to distances of water source to cocoa farms.
Concentrations of potassium recorded in the study ranged between 2.90 to $4.45 \mathrm{mg} / \mathrm{L}$ with a mean of $3.55 \pm 0.57 \mathrm{mg} / \mathrm{L}$. There were no significant differences $(p>0.05)$ in potassium among the various distances of water source to cocoa farms within the study period. All the water samples analysed from the various sites within the distances recorded potassium concentrations below the WHO (2004) permissible limit of $30 \mathrm{mg} / \mathrm{L}$ for drinking water. The $\mathrm{Na}^{+}$and $\mathrm{K}^{+}$concentrations recorded in this study pose neither physiological nor aesthetic problem to water usage for drinking or domestic purposes within the study area.

\section{Organophosphorus pesticide residues in soil samples}

Table 2 presents the summary results of the organophosphorus pesticide residues detected in soil samples from the study area. Three out of the 13 organophosphorus pesticides namely; chlorpyrifos, profenefos and pirimiphos-methyl were detected in the soil samples. They were in the order: chlorpyrifos $>$ pirimiphos-methyl $>$ profenefos in terms of the concentration levels. Results revealed recovery range between $70-94 \%$ for all the pesticides detected indicating that the analytical process used was efficient and reproducible. The limit of detection (LOD) was $0.01 \mathrm{mg} / \mathrm{kg}$.

Chlorpyrifos occurred in $56.3 \%$ of the soil samples analysed. The measured mean concentrations ranged from $0.01 \mathrm{mg} / \mathrm{kg}$ at S3 to $0.04 \mathrm{mg} / \mathrm{kg}$ at S1, with a total sites mean concentration of $0.03 \pm 0.01 \mathrm{mg} / \mathrm{kg}$. Statistically, the concentrations of chlorpyrifos recorded in the soil samples were not significantly $(p>0.05)$ different among the various sites. However, the mean concentration of chlorpyrifos recorded in soils from S1 $(0.04 \mathrm{mg} /$ $\mathrm{kg}$ ) was higher than the United States (US) maximum residue limit of $0.03 \mathrm{mg} / \mathrm{kg}$ for agricultural soils. On the other hand, the mean values recorded at $\mathrm{S} 2(0.03 \mathrm{mg} / \mathrm{kg})$ and S4 $(0.03 \mathrm{mg} / \mathrm{kg})$ were comparable or within the US Maximum Residue Limit of $0.03 \mathrm{mg} / \mathrm{kg}$. Chlorpyrifos is a broad-spectrum organophosphorus pesticide. Chlorpyrifos under trade name Dursban $4 \mathrm{R}$, is registered for use in Ghana (Botwe et al. (2012). The occurrence of

Table 2 Range, mean and standard deviation of organophosphorus pesticides in soil of cocoa farms from Dormaa West District, Ghana

\begin{tabular}{|c|c|c|c|c|c|c|c|c|c|c|}
\hline \multirow{2}{*}{$\begin{array}{l}\text { Sites } \\
\text { Pesticides (mg/kg) }\end{array}$} & \multicolumn{2}{|c|}{ Nkrankwanta (S1) } & \multicolumn{2}{|c|}{ Diabaa (S2) } & \multicolumn{2}{|c|}{ Krakrom (S3) } & \multicolumn{2}{|c|}{ Kwakuanya (S4) } & \multirow{2}{*}{$\begin{array}{l}\text { Total means } \\
\text { Mean } \pm \text { SD }\end{array}$} & \multirow[t]{2}{*}{ US MRLs } \\
\hline & Range & Mean \pm SD & Range & Mean \pm SD & Range & Mean \pm SD & Range & Mean \pm SD & & \\
\hline Chlorpyrifos (mg/kg) & $0.03-0.06$ & $0.04 \pm 0.02$ & ND-0.04 & $0.03 \pm 0.01$ & ND-0.01 & $0.01 \pm-$ & ND-0.03 & $0.03 \pm-$ & $0.03 \pm 0.01$ & 0.03 \\
\hline Profenofos (mg/kg) & ND-0.02 & $0.02 \pm-$ & ND-0.04 & $0.04 \pm-$ & ND-0.04 & $0.04 \pm-$ & ND-0.02 & $0.02 \pm-$ & $0.03 \pm 0.01$ & 0.05 \\
\hline $\begin{array}{l}\text { Pirimiphos-methyl (mg/ } \\
\text { kg) }\end{array}$ & ND-0.05 & $0.04 \pm 0.01$ & ND-0.02 & $0.02 \pm-$ & ND-0.02 & $0.02 \pm-$ & ND-0.01 & $0.01 \pm-$ & $0.02 \pm 0.01$ & 0.03 \\
\hline
\end{tabular}

SD standard deviation, ND non-detected/below detection, US MRLs United States maximum residue limits for pesticides in agricultural soils, Limit of detection $=0.010 \mathrm{mg} / \mathrm{kg}$ 
chlorpyrifos in soil samples could be as result of their use in cocoa production. The mean values of chlorpyrifos recorded in this work were however, lower than the values reported by Akan et al. (2013) in soils samples from Alau dam and Gongulong Agricultural area, Boron State, Nigeria. Additionally, the mean chlorpyrifos residue levels $(0.01-0.04 \mathrm{mg} / \mathrm{kg})$ recorded in this study were far lower than the range of $0.52-0.97 \mathrm{mg} / \mathrm{kg}$ reported by Mahmud et al. (2015) in soil samples from Gashua, Bade Local Government Area Yobe State, in Nigeria. This may be due to difference in the geology and extent of soil pollution by pesticides.

Similarly, profenofos occurred in $37.5 \%$ of soil samples analysed. The measured concentrations of profenofos ranged from $0.02 \mathrm{mg} / \mathrm{kg}$ at $\mathrm{S} 1$ and $\mathrm{S} 4$ to $0.04 \mathrm{mg} / \mathrm{kg}$ at S2 and S3, with a mean value of $0.03 \pm 0.01 \mathrm{mg} / \mathrm{kg}$. There were no significant sites differences $(p>0.05)$ in profenofos concentrations. The mean concentrations of profenofos recorded at all sites were below the US MRL of $0.05 \mathrm{mg} / \mathrm{kg}$ for agricultural soils. In a similar study Supriyadi et al. (2015), reported profenefos concentrations that were relatively higher than the mean values reported in this work. This could be due to the extent of pollution of soils with profenefos containing pesticides in that study area.

Pirimiphos-methyl was detected in $43.8 \%$ of the soil samples analysed. The measured mean concentrations ranged from $0.01 \mathrm{mg} / \mathrm{kg}$ at $\mathrm{S} 4$ to $0.04 \mathrm{mg} / \mathrm{kg}$ at $\mathrm{S} 1$, with a total sites average of $0.02 \pm 0.01 \mathrm{mg} / \mathrm{kg}$. There were no significant sites differences $(p>0.05)$ in pirimiphosmethyl concentrations. The mean concentrations of pirimiphos-methyl recorded at the various sampled sites were found to be within the United States (US) MRL of $0.03 \mathrm{mg} / \mathrm{kg}$ for agricultural soil except S1 $(0.04 \mathrm{mg} / \mathrm{kg})$ which recorded a mean concentration above the US MRL for agricultural soils.

The detection of organophosphorus pesticides in the soil samples suggests that cocoa farmers in the study area use organophosphate pesticides in significant quantities. These pesticides may have found their way into the soils via spray drift during cocoa tree spraying, wash-off from treated cocoa trees and wrong disposal of left over spray solution, sprayer wash water and used pesticide containers.

\section{Organophosphorus pesticide residues in water samples}

Table 3 summarizes the results of the organophosphorus pesticide residues detected in water samples from the various distances from cocoa farms in the study area. Three out of the 13 organophosphorus compounds namely; chlorpyrifos, diazinon and pirimiphos-methyl were detected in the water samples analysed from the various sites. Results revealed recovery range between $70-94 \%$ for all the pesticides detected. These recovery values show that the method used is reproducible. The limit of detection (LOD) was $0.01 \mu \mathrm{g} / \mathrm{L}$. Generally, concentrations of pesticide residues were below detection limit at the control site which was above $30 \mathrm{~m}$ distance from cocoa farms.

Chlorpyrifos was the most frequently detected pesticide residue, occurring in $42.1 \%$ of water samples analysed. The average concentrations of chlorpyrifos recorded at the various distances ranged from below detection to $0.05 \mu \mathrm{g} / \mathrm{L}$ with a mean value of $0.04 \pm 0.01 \mu \mathrm{g} / \mathrm{L}$. There were however no significant differences $(p>0.05)$ in chlorpyrifos concentrations in relation to distances of water sources to cocoa farms. However, with the exception of samples from S1 $(0.05 \mu \mathrm{g} / \mathrm{L}), \mathrm{S} 2(0.06 \mu \mathrm{g} / \mathrm{L})$ and S4 $(0.06 \mu \mathrm{g} / \mathrm{L})$ at distances, $16-30 \mathrm{~m}$, all the other sites within the various distances recorded mean values below the World Health Organization (WHO) Maximum Residue Limit (MRL) value of $0.05 \mu \mathrm{g} / \mathrm{L}$ for drinking water. The mean chlorpyrifos residue levels recorded in this study were far lower than the range of not detected (ND)$1545.1 \mu \mathrm{g} / \mathrm{L}$ reported by Essumang et al. (2009) in water samples from Lagoons in Ghana. In addition, the total mean value of chlorpyrifos $(0.04 \mu \mathrm{g} / \mathrm{L})$ recorded in this study was in line with the mean value of $0.04153 \mu \mathrm{g} / \mathrm{L}$ reported by Malhat and Nasr (2013) in water samples from the Nile River tributaries, in Egypt. On the other hand, this findings is contrary to the results of Botwe et al. (2012) which recorded no chlorpyrifos residue in 18

Table 3 Range, mean and standard deviation of organophosphorus pesticides in water samples with respect to the various distance categories from the nearest cocoa farms in Dormaa West District, Ghana

\begin{tabular}{|c|c|c|c|c|c|c|c|c|}
\hline \multirow{2}{*}{$\begin{array}{l}\text { Distance (m) } \\
\text { Pesticides }\end{array}$} & \multicolumn{2}{|l|}{$0-15 \mathrm{~m}$} & \multicolumn{2}{|l|}{$16-30 \mathrm{~m}$} & \multicolumn{2}{|c|}{ Above $30 \mathrm{~m}$} & \multirow{2}{*}{$\begin{array}{l}\text { Total means } \\
\text { Mean } \pm \text { SD }\end{array}$} & \multirow[t]{2}{*}{ WHO MRLs } \\
\hline & Range & Mean \pm SD & Range & Mean \pm SD & Range & Mean \pm SD & & \\
\hline Chlorpyrifos ( $\mu \mathrm{g} / \mathrm{L})$ & ND-0.03 & $0.03 \pm-$ & $0.02-0.06$ & $0.05 \pm 0.02$ & ND & ND & $0.04 \pm 0.01$ & 0.05 \\
\hline Diazinon $(\mu \mathrm{g} / \mathrm{L})$ & $0.03-0.06$ & $0.04 \pm 0.02$ & $0.03-0.04$ & $0.04 \pm 0.01$ & ND & ND & $0.04 \pm 0.01$ & 0.05 \\
\hline Pirimiphos-methyl ( $\mu \mathrm{g} / \mathrm{L})$ & $0.02-0.04$ & $0.03 \pm 0.01$ & $0.01-0.05$ & $0.03 \pm 0.02$ & ND & ND & $0.03 \pm-$ & 6.00 \\
\hline
\end{tabular}

SD standard deviation and ND non-detected/below detection, WHO MRLs World Health Organization maximum residue limit for pesticides in water, Limit of detection $=0.01 \mu \mathrm{g} / \mathrm{L}$ 
hand dug wells in and around vegetable plantations in the Ofinso District of Ghana. This difference may be due to the extent of pesticides use which contains chlorpyrifos as active ingredient in the study area of this research. The presence of chlorpyrifos in the water samples analysed suggests the use of the pesticides containing chlorpyrifos as active ingredient in cocoa production in the study area as it was also detected in the soil samples.

Diazinon was detected in $31.6 \%$ of water samples analysed with a mean concentration of $0.04 \pm 0.01 \mu \mathrm{g} / \mathrm{L}$. The mean concentration of diazinon recorded among the various distance categories ranged from below detection to $0.04 \mu \mathrm{g} / \mathrm{L}$. Similarly, there were no significant differences $(p>0.05)$ in diazinon concentrations in relation to distances of water sources to cocoa farms. However, with the exception of S4 $(0.06 \mu \mathrm{g} / \mathrm{L})$ at a distance $0-15 \mathrm{~m}$, all the other sites within the various distances recorded mean values below the WHO MRL of $0.05 \mu \mathrm{g} / \mathrm{L}$ for drinking water. According to Sosan et al. (2008), diazinon is a category II insecticide which is moderately hazardous with acute oral lethal Dose of $\geq 50 \leq 500$ and is capable of causing acute and chronic intoxication. The diazinon mean value recorded in this work was lower than the mean value of $16.65 \mu \mathrm{g} / \mathrm{L}$ reported by Sosan et al. (2008) in domestic water sources from cocoa farms in SouthWestern Nigeria. Also, the mean diazinon residue levels (below detection- $0.04 \mu \mathrm{g} / \mathrm{L}$ ) as shown in Table 3 were far lower than the range of ND-185.5 $\mu \mathrm{g} / \mathrm{L}$ that was reported by Essumang et al. (2009) in water samples from Lagoons in Ghana. The occurrence and concentrations of diazinon in some of the water samples was surprising, since it was not detected in soils samples. This suggests possible contamination through spray drift during pesticides application and possible pesticides misuse as those water sources were in close proximity to cocoa farms.

Pirimiphos-methyl occurred in $27 \%$ of the water samples analysed. The range of pirimiphos-methyl concentrations recorded was from below detection to $0.03 \mu \mathrm{g} / \mathrm{L}$ with a mean value of $0.03 \mu \mathrm{g} / \mathrm{L}$. There were no significant differences $(p>0.05)$ in pirimiphos-methyl concentrations in relation to distances of water sources to cocoa farms. However, the mean concentrations of pirimiphos-methyl recorded at sampled sites with detectable residues, were found to be below the WHO permissible residue limit of $6.00 \mu \mathrm{g} / \mathrm{L}$ for drinking water. The detection of pirimiphos-methyl in the water samples suggests the use of pesticides with pirimiphos-methyl as its active ingredient in the control of cocoa pests and diseases by farmers as it was also detected in the soil samples.

The presence of organophosphorus pesticides in the water samples analysed could be due to direct overspray, atmospheric transport of volatilized pesticides or wind drift, direct spillage, pesticide misuse by farmers, improper disposal of pesticides containers, leaching and run-off from farms sprayed with pesticides.

\section{Relationship between water physico-chemical properties and pesticide residues detected}

The relationship between water properties and pesticides residues detected were analysed using the Pearson correlation (Table 4). For correlation significance, the criteria value of probabilities $(p<0.05$ and $p<0.01)$ was used. A positive significant correlation was observed between $\mathrm{pH}$ and (diazinon and pirimiphos-methyl), EC and (diazinon and chlorpyrifos), TDS and (diazinon and chlorpyrifos), TSS and (diazinon), ammonia and (diazinon), phosphate and (pirimiphos-methyl), sodium and (chlorpyrifos) and potassium and (pirimiphos-methyl). On the other hand, temperature and pirimiphos-methyl correlated negatively.

The strong positive correlation between $\mathrm{pH}$ and (diazinon and pirimiphos-methyl) and EC and (diazinon and chlorpyrifos) indicates that $\mathrm{pH}$ and $\mathrm{EC}$ of water could have enhanced the adsorption of these pesticide compounds. Thus, increase in $\mathrm{pH}$ and $\mathrm{EC}$ resulted in a corresponding increase in concentrations of diazion and pirimiphos-methyl, and diazinon and chlorpyrifos respectively. In addition, the strong positive correlation between TDS and (diazinon and chlorpyrifos) and TSS and (diazinon) suggests that these pesticides residue levels in water possibly increased with TDS and TSS content of the water. Also, the positive correlation between ammonia and (diazinon), phosphate and

Table 4 Values of Pearson's correlation between water physicochemical parameters and pesticide residues detected

\begin{tabular}{lcllllllllll}
\hline & EC & $\mathbf{p H}$ & TDS & Temp & TSS & Turbidity & $\mathbf{N O}_{\mathbf{3}}{ }^{-}$ & $\mathbf{N H}_{\mathbf{3}}$ & $\mathbf{P O}_{\mathbf{4}}{ }^{\mathbf{3}}$ & $\mathbf{N a}^{+}$ & $\mathbf{K}^{+}$ \\
\hline Diazinon & $0.984^{* *}$ & $0.977^{*}$ & $0.978^{*}$ & -0.116 & $0.981^{* *}$ & -0.106 & -0.274 & $0.997^{* *}$ & -0.031 & 0.303 & 0.064 \\
Chlorpyrifos & $0.748^{*}$ & 0.286 & $0.745^{*}$ & 0.140 & 0.027 & 0.136 & -0.368 & 0.271 & -0.032 & $0.739^{*}$ & 0.474 \\
Pirimisphos-methyl & -0.437 & $0.614^{*}$ & -0.433 & $-0.806^{* *}$ & 0.057 & 0.449 & -0.368 & 0.307 & $0.820^{* *}$ & -0.382 & $0.935^{* *}$ \\
\hline
\end{tabular}

Temp temperature, EC electrical conductivity, TDS total dissolved solids, TSS total suspended solids, $\mathrm{PO}_{4}{ }^{3-}$ phosphate, $\mathrm{NO}_{3}{ }^{-}$nitrate, $\mathrm{NH}_{3}$ ammonia

* Correlation is significant at the 0.05 level (2-tailed)

** Correlation is significant at the 0.01 level (2-tailed) 
(pirimiphos-methyl), sodium and (chlorpyrifos), and potassium and (pirimiphos-methyl) suggests that these nutrients in water have significant influence on the distribution of pesticides and an increase in the level of these nutrients resulted in a corresponding increase in their respective pesticide residues. On the other hand, the negative correlation between temperature and pirimiphos-methyl indicates that pirimiphos-methyl pesticide residue levels in water decrease with increase in water temperature and vice versa. This could be due to decomposition of pirimiphos-methyl pesticide with increase in water temperature.

\section{Conclusions}

The results of this study have provided an insight into the levels of organophosphorus pesticide residues contamination in soils of cocoa farms and drinking water sources in and around cocoa farms in the Dormaa West District of Ghana. From the study, four organophosphorus pesticide residues (diazinon, chlorpyrifos, pirimiphos-methyl and profenofos) were detected in the soil and water samples analysed. Chlorpyrifos was the most detected organophosphorus residue in soil and water samples. The presence of organophosphorus pesticides suggests the use of the pesticides by cocoa farmers in the study area and that could be attributed to the fact that most of these pesticides were registered for use in Ghana for agricultural purposes (Environmental Protection Agency (EPA) 2009).

Concentrations of organophosphorus in the soil samples from the various sites were generally below and within the US MRLs for agricultural soils, except soils from Nkrankwanta (S1) which recorded mean chlorpyrifos and pirimiphos-methyl concentrations which were above their respective US MRLs for agricultural soils. The occurrence of organophosphorus pesticide compounds in the soil samples from these cocoa farms is worrisome. Apart from the potential danger these pesticide residues may pose to soil organisms, there is also the possibility of translocation of these residues from the soil into the cocoa beans and other crops (that are commonly intercropped with cocoa) through the root system posing health risks to consumers of these produce. In addition, water bodies are likely to be contaminated with these pesticide residues through runoff and leaching from soils in these farms.

The concentration of organophosphorus pesticide residues in the water samples decreased with increase in distance of water source to cocoa farms in the order; 0-15 $\mathrm{m}>16-30 \mathrm{~m}>$ above $30 \mathrm{~m}$ (control). Although pirimiphos-methyl concentrations recorded in water samples within the various distance categories were below the WHO MRLs for drinking water, chlorpyrifos and diazinon exceeded their respective WHO MRLs in water samples at S2 $(0.06 \mu \mathrm{g} / \mathrm{L})$ and $\mathrm{S} 4(0.06 \mu \mathrm{g} / \mathrm{L})$ at distance $16-30$ and at $S 4(0.06 \mu \mathrm{g} / \mathrm{L})$ at distance $0-15 \mathrm{~m}$ respectively.

The results therefore suggest that, organophosphorus pesticide residues concentrations in wells within the various distances of the study area may not pose health hazards to cocoa farmers' households and their entire community who utilize water from these sources except for water from wells from S2 and S4 (at distances 16-30 $\mathrm{m}$ and S4 at distances 0-15 m).

Routine monitoring of pesticide residues in the study area is necessary for the prevention, control and reduction of environmental pollution, so as to minimize health risks to humans. In addition, hand dug wells for domestic use should be sited above $30 \mathrm{~m}$ from cocoa farms to reduce potential pesticide contamination as most of the water samples analysed within distances 0-30 m were found to be contaminated with pesticide residues. Farmer sensitization on safe pesticide use should be intensified to reduce the levels of pesticide residues in soils and in drinking water sources as poor practices such as improper disposal of empty pesticides containers were observed in the study area.

\section{Abbreviations}

CP: gas chromatograph; MRLs: maximum residue levels; EPA: Environmental Protection Agency; TSS: total suspended solids; TDS: total dissolved solids; ANOVA: analysis of variance; SPSS: statistical package for social sciences; WHO: World Health Organization; S1: Nkrankwanta; S2: Diabaa; S3: Krakrom; S4: Kwakuanya.

\section{Authors' contributions}

$\mathrm{EDO}, \mathrm{FMBY}$ and $C \mathrm{G}$ designed the study and wrote the protocol, EDO collected data and conducted data analysis, FMBY and EDO, drafted the manuscript, GD and FMBY reviewed and contributed to the writing of manuscript. All authors read and approved the final manuscript.

\section{Author details}

${ }^{1}$ Institute for Environment and Sanitation Studies (IESS), University of Ghana, P. O. Box 209, Legon, Accra, Ghana. ${ }^{2}$ Department of Chemistry, Kwame Nkrumah University of Science and Technology, Kumasi, Ghana.

\section{Acknowledgements}

We wish to thank Mr. Emmanuel Ansah of the Ecological Laboratory (ECOLAB), University of Ghana, Legon and Mr. Samuel Kofi Frimpong of the Ghana Standards Authority's Pesticide Residues Laboratory for their immense contribution during the laboratory analysis.

\section{Competing interests}

The authors declare that they have no competing interests.

Received: 23 December 2015 Accepted: 22 February 2016 Published online: 01 March 2016

\section{References}

Abekoe MK, Obeng-Ofori D, Egyir IS (2002) Technography of cocoa in the forest zone of Ghana. In: Report presented at the- convergence of Sciences International Workshop, Benin. Unpublished project document, p 29 
Afful S, Anim AK, Serfor-Armah Y (2010) Spectrum of Organochlorine pesticide residues in fish samples from the Densu Basin. Res J Environ Earth Sci 2(3):133-138

Afful S, Awudza JAM, Osae S, Twumasi SK (2013) Assessment of synthetic pyrethroids residues in the waters and sediments from the Weija Lake in Ghana. Eur Chem Bull 2(4):183-187

Agbeve SK, Osei-Fosu P, Carboo D (2014) Levels of organochlorine pesticide residues in Mondia whitei, a medicinal plant used in traditional medicine for erectile dysfunction in Ghana. Int J Adv Agric Res 1:9-16

Akan JC, Jafiya L, Mohammed Z, Abdulrahman FI (2013) Organophosphorus pesticide residues in vegetable and soil samples from Alau Dam and Gongulong agricultural areas, Borno State, Nigeria. Int J Environ Monit Anal 1(2):58. doi:10.11648/j.ijema.20130102.14

Aktar MW, Sengupta D, Chowdhury A (2009) Impact of pesticides use in agriculture: their benefits and hazards. Interdiscip Toxicol 2(1):1-12. doi:10.2478/v10102-009-0001-7

American Public Health Association (APHA)(1998) Standard methods for the examination of water and waste water, 20th ed. American Public Health Association/American Water Works Association/Water Environment Federation, Washington DC, USA

Apau J, Dodoo DK (2010) Lindane and Propoxur residues in cocoa from Central Region of Ghana. J Sci Technol 30(3):15-20

Bentum JK, Essumang DK, Dodoo DK (2006) Lindane and propuxur residues in the top soils of some cocoa growing areas in five districts of the Central Region of Ghana. Bull Chem Soc Ethiop 20:193-199. doi:10.4314/bcse. v20i2.21161

Botchway F (2000) Analysis of pesticide residues in Ghana's exportable cocoa. A higher certificate project submitted to Institute of Science and Technology London, 44-45

Botwe BO, Ntow WJ, Nyarko E (2012) Pesticide contamination in groundwater and streams draining vegetable plantations in the Ofinso District, Ghana. In: Dr. Maria C. Hernandez Soriano (ed) Soil health and land use management. p 51-66

Cocco P, Satta G, Dubois S, Pili C, Pilleri M, Zucca M, Mannetje AM, Becker N, Benavente $Y$, Sanjose SD, Foretova L, Staines A, Maynadie M, Nieters A, Brennan P, Miligi L, Ennas MG, Boffetta P (2013) Lymphoma risk and occupational exposure to pesticides: results of the epilymph study. Occup Environ Med 70:91-98. doi:10.1136/oemed-2011-100382.110

Dankyi E, Gordon C, Carboo D, Fomsgaard IS (2014) Quantification of neonicotinoid insecticide residues in soils from cocoa plantations using a QuEChERS extraction procedure and LC-MS/MS. Sci Total Environ 499:276-283. doi:10.1016/j.scitotenv.2014.08.051

Environmental Protection Agency (EPA) (Ghana) (2009) Register of pesticides as at 31 st December 2009 under Part 11 of the environmental protection agency act (Act 490), p 1994

Essumang DK, Togoh GK, Chokky L (2009) Pesticide residues in the water and fish (Lagoon Tilapia) samples from lagoons in Ghana. Bull Chem Soc Ethiop 23:19-27

Ewusi A, Obiri-Yeboah S, Voigt HJ, Asabere SB, Bempah CK (2013) Groundwater quality assessment for drinking and irrigation purposes in Obuasi Municipality of Ghana, a preliminary study. Res J Environ Earth Sci 5(1):6-17

Fianko JR, Donkor A, Lowor ST, Yeboah PO (2011) Agrochemicals and the Ghanaian environment, a review. J Environ Prot (Irvine, Calif) 2:221-230. doi:10.4236/jep.2011.23026

Fianko JR, Laar C, Osei J, Anim AK, Gibrilla A, Adomako D (2013) Evaluation of some heavy metal loading in the Kpeshi lagoon, Ghana. Apply water Sci 3:311-319. doi:10.1007/s13201-013-0083-4

Frimpong KS, Yeboah P, Fletcher JJ, Adomako D, Osei-Fosu P, Acheampong K (2012a) Organochlorine pesticides levels in fermented dried cocoa beans produced in Ghana. Elixir Agric 44:7280-7284

Frimpong KS, Yeboah P, Fletcher JJ, Adomako D, Pwamang J (2012b) Assessment of organochlorine pesticides residues in cocoa beans from Ghana. Elixir Food Sci 50:10257-10261
Frimpong KS, Yeboah PO, Fletcher JJ, Pwamang J, Adomako D (2012C) Assessment of synthetic pyrethroids pesticides residues in cocoa beans from Ghana. Elixir Food Sci 49:9871-9875

Frimpong KS, Yeboah PO, Fletcher JJ, Pwamang J, Adomako D (2012d) Multi-residue levels of Organophosphorous pesticides in cocoa beans produced from Ghana. Elixir Food Sci 47:8721-8725

Frimpong KS, Gbeddy G, Doyi I, Arye-Quaye F, Kokroko W, Asamoah CO (2013) Efficient method development for atrazine determination in soil samples. An Indian J Environ Sci 8(7):264-267. doi:10.1039/c2ee23482c

Ghana Statistical Service (2014) 2010 Population and housing census: district analytical report of Dormaa West

Gill HK, Garg H (2014) Pesticides: environmental impacts and management strategies. In: Dr. Sonia Soloneski (ed) Pesticides—toxic aspects. InTech, p 188-230

Harris BL, Hoffman DW, Mazac FJ (1996) Reducing the risk of ground water contamination by improving household wastewater treatment

Kortatsi BK (2007) Groundwater quality in the Wassa West District of the Western Region of Ghana. West African J Appl Ecol 11(1):26-36. doi:10.4314/ wajae.v11i1.45729

Langmuir D (1997) Aqueous environmental geochemical: upper Saddle River. Prentice Hall, New Jersey

Mahmud MM, Akan JC, Mohammed Z, Battah N (2015) Assessment of organophosphorus and pyrethroid pesticide residues in watermelon (citrulus lanatus) and soil samples from Gashua, bade local government area Yobe State, Nigeria. J Environ Pollut Hum Heal 3:52-61. doi:10.12691/ jephh-3-3-1

Malhat F, Nasr I (2013) Monitoring of Organophosphorous pesticides residues in water from the Nile River Tributaries, Egypt. Am J Water Resour 1(1):1-4. doi:10.12691/ajwr-1-1-1

Mesnage R, Clair E, de Vendômois JS, Seralini GE (2010) Two cases of birth defects overlapping Stratton-Parker syndrome after multiple pesticide exposure. Occup Environ Med 67(5):359. doi:10.1136/oem.2009.052969

Nkansah MA, Boadi NO, Badu M (2010) Assessment of the Quality of water from hand-dug wells in Ghana. Environ Health Insights 4:7-12. doi:10.4137/EHI.S3149

Ntiamoah A, Afrane G (2008) Environmental impacts of cocoa production and processing in Ghana: life cycle assessment approach. J Clean Prod 16(16):1735-1740. doi:10.1016/j.jclepro.2007.11.004

Owusu-Ansah E, Koranteng-Addo JE, Boamponsem LK, Menlah E, Abole E (2010) Assessment of lindane pesticide residue in cocoa beans in the Twifo Praso district of Ghana. J Chem Pharm Res 2(4):580-587

Sosan MB, Akingbohungbe AE, Ojo IAO, Durosinmi MA (2008) Insecticide residues in the blood serum and domestic water source of cacao farmers in Southwestern Nigeria. Chemosphere 72(5):781-784. doi:10.1016/j. chemosphere.2008.03.015

Supriyadi S, Utami AD, Widijanto H, Sumani S (2015) Organophosphate residue in different land use in Mojogedang Karanganyar Central Java Indonesia. Mod Appl Sci 9:87-96. doi:10.5539/mas.v9n6p87

Syoku An (2006) Method as specified by Multi-residue method for agricultural chemicals by GC/MS. as released by the Department of Food Safety, Ministry of Health, Labour and Welfare, Japan, (No. 0124001)

Tanner CM, Kamel F, Ross GW, Hoppin JA, Goldman SM, Korell M, Marras C, Bhudhikanok GS, Meike K, Chade AR, Comyns K, Richards MB, Meng C Priestley B, Fernandez HH, Langton W (2011) Rotenone, paraquat, and parkinson's Disease. Environ Health Perspect 119:866-872. doi:10.1289/ ehp.1002839

Tay CK (2007) Chemical characteristics of groundwater in the Akatsi and Ketu Districts of the Volta Region, Ghana. West African J Appl Ecol 11(1):3-25. doi:10.4314/wajae.v11i1.45731

WHO (1998) World Health Organization guideline for drinking water quality. WHO Summit, Geneva

WHO (2004) Guidelines for Drinking-water quality, 3rd edn. World Health Organization, Geneva 